\title{
Espécies de Hesperandra (Tavandra) Santos-Silva, com pilosidade abundante no metasterno (Coleoptera, Cerambycidae, Parandrinae)
}

\author{
Antonio Santos-Silva ${ }^{1}$ \\ ${ }^{1}$ Museu de Zoologia, Universidade de São Paulo. Caixa Postal 42594, 04299-970 São Paulo, São Paulo, Brasil.

\begin{abstract}
Species of Hesperandra (Tavandra) Santos-Silva, with abundant pilosity on metasternum (Coleoptera, Cerambycidae, Parandrinae). Parandra scaritoides Thomson, 1861 is removed from synonymy of Hesperandra colombica (White, 1853) and reinstated. Both species are redescribed. New species described from Venezuela: H. solangeae. A key to the three species is added.
\end{abstract}

KEY WORDS. Cerambycidae, Coleoptera, Hesperandra, Parandrinae, taxonomy.

Entre os Parandrinae americanos, poucas espécies apresentam pêlos abundantes no metasterno. Freqüentemente, as espécies que apresentam esse caráter, habitam regiões montanhosas, como ocorre com as que são estudadas neste trabalho: Hesperandra scaritoides, $H$. colombica e $H$. solangeae sp. nov. Essas três espécies pertencem ao subgênero Hesperandra (Tavandra) SantosSilva, 2003, que se caracteriza, principalmente, por apresentar carena estreita na região ventral das genas. Nenhuma outra espécie desse subgênero apresenta pilosidade abundante no metasterno.

As siglas utilizadas no texto correspondem: (DZUP) Departamento de Zoologia, Universidade Federal do Paraná, Curitiba; (GMIC) Gilberto Mendonza Insect Collection, Bogotá; (IAHC) Instituto de Investigaciones de Recursos Biológicos "Alexander von Humboldt", Villa de Leyva; (MNHN) Muséum National d'Histoire Naturelle, Paris; (MUJB) Museo Universidad Javeriana, Bogotá; (MZSP) Museu de Zoologia, Universidade de São Paulo, São Paulo. As medidas são fornecidas em milímetros.

\section{Chave para as espécies de $H$. (Tavandra) com pilosidade abundante no metasterno}

1. Pontuação elitral muito grossa (Figs 1-2); margem interna da mandíbula dos machos (Fig. 3) com um dente grande, de ápice arredondado, localizado entre o meio e o dente apical interno H. colombica

1'. Pontuação elitral mais fina (Figs 6-7, 16); margem interna da mandíbula dos machos (Figs 10-11, 17) com dente aguçado, localizado aproximadamente no meio

2. Margens laterais do pronoto dos machos (Fig. 6) paralelas na metade anterior; tíbias, principalmente as anteriores, nos dois sexos, fortemente dilatadas para o ápice (Fig. 20)

H. scaritoides
2'. Margens laterais do pronoto dos machos (Fig. 16) suavemente convergentes para o ápice, na metade anterior; tíbias pouco alargadas para o ápice (Fig. 21) ............. H. solangeae

\section{Hesperandra colombica (White, 1853) \\ Figs 1-5, 19}

Parandra colombica White, 1853: 3; Rojas, 1866: 237; Gemminger \& Harold, 1872: 2751 (cat.); Kirsch, 1889: 50 (distr.); Lameere, 1902: 73; Blackwelder, 1946: 551 (cat.); Maes et al., 1994: 3 (distr.).

Parandra columbica (sic); Lacordaire, 1869: 23 (nota); Prudhomme, 1906: 33 (distr.).

Parandra (Archandra) colombica; Lameere, 1913: 4 (cat.); 1919: 15; Rosales, 1966: 37; Chemsak \& Linsley, 1982: 1 (cat.); Chemsak et al., 1992: 13 (cat.).

Parandra (Hesperandra) colombica; Arigony, 1978: 140; Monné \& Giesbert, 1994: 1 (cat.); Monné, 1994: 5 (cat.); Martinez, 2000: 83.

Parandra Gyllenhalii (sic) Thomson, 1867: 110; Lacordaire, 1869: 23 (nota); Thomson, 1878: 4 (tipo).

Parandra Gyllenhali (sic); Gemminger \& Harold, 1872: 2752 (cat.); Lameere, 1902: 73 (syn.).

Redescrição. Macho (Fig. 1). Tegumento castanho-escuro. Vértice convexo, com pontos moderadamente grossos e concentrados. Pontuação da fronte mais esparsa e fina do que a do vértice. Região posterior dos olhos com pontos profundos, confluentes e maiores que os do vértice. Fronte com sulco raso e longitudinal. Ápice do clípeo-labro não ultrapassa os cantos anteriores da cabeça. Carena ocular não-destacada. Região lateral das genas com pontos abundantes e bem marcados; depressão lateral profunda e alongada; ápice arredondado, pouco projetado e pontuado na área ventral. Submento (Fig. 

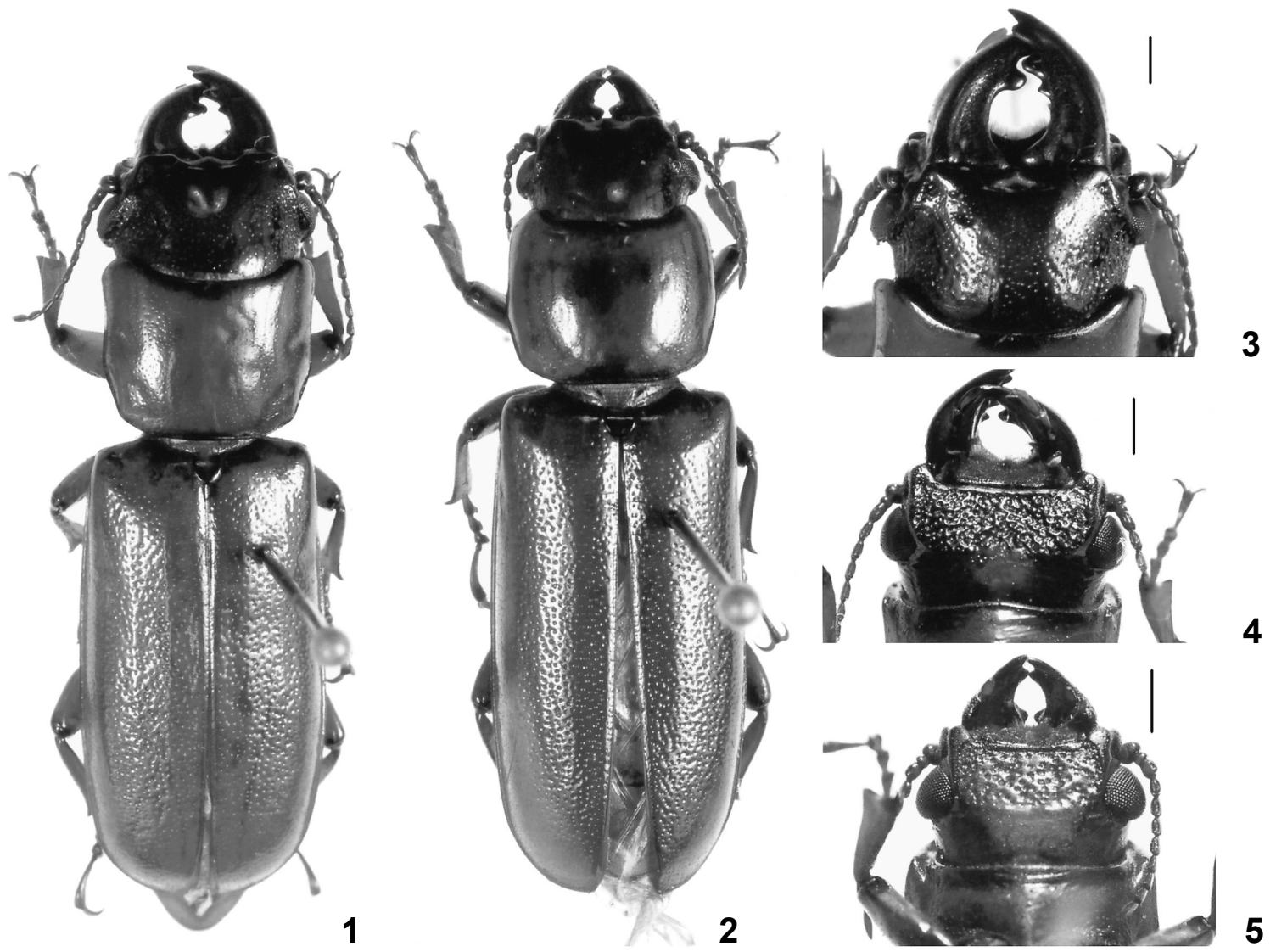

Figuras 1-5. Hesperandra colombica, vista dorsal: (1) macho, comprimento 26,7 mm; (2) fêmea, comprimento 26,8 mm; (3-4) macho: (3) mandíbula, vista dorsal; (4) submento; (5) fêmea, submento. Barra $=1 \mathrm{~mm}$.

4) como em H. solangeae. Mento e lígula com pilosidade longa e abundante. Palpos maxilares longos (atingem o terço apical das mandíbulas). Olhos grosseiramente facetados, fortemente estreitados superiormente; borda posterior saliente. Mandíbulas (Fig. 3) falciformes, não-fortemente estreitadas para o ápice; carena dorsal bem marcada da base até o terço apical; área dorsal cerradamente pontuada (principalmente em direção ao ápice) e com pêlos microscópicos; ápice liso; dente apical externo aguçado; dente apical externo aguçado; dente apical interno arredondado e mais curto que o externo; face dorso-interna lisa e larga até o dente apical interno, estreitada em direção à base; dente da margem interna grande, arredondado, localizado no terço apical (alguns exemplares possuem um dente menor, aguçado, localizado aproximadamente no meio, numa ou nas duas mandíbulas); margem interna orlada com pêlos diminutos; face látero-externa com pontos grandes esparsos nos dois terços basais e pequenos e concentrados no terço apical; área ventral lisa e com depressão onde se alojam os palpos. Antenas atingem o terço posterior do protórax; antenômeros III-XI mais longos que largos e com a carena da área sensorial saliente em vista lateral; antenômeros III-X com pêlos curtos, principalmente nos ápices ventral e dorsal; antenômero XI um terço mais longo que o $X$.
Protórax subquadrado, ligeiramente mais largo que longo; marginação lateral completa e enegrecida; ângulos anteriores arredondados; ângulos posteriores obtusos. Pronoto fortemente côncavo na margem anterior; margem posterior reta; margens laterais côncavas na metade anterior e obliquas até os ângulos posteriores; áreas laterais com pontuação nítida; disco com pontos microscópicos. Prosterno com pontos rasos e esparsos; pilosidade restrita à área posterior das procoxas. Processo prosternal com ápice largo e carena central. Mesosterno com pontos e pêlos cerrados nas laterais, glabro e liso no disco. Mesepisternos pontuados e pilosos em toda extensão. Mesepimeros com pontos e pêlos apenas na margem contígua ao metasterno. Metasterno com pontuação e pilosidade mais concentrada nas laterais e terço basal; disco metasternal quase glabro. Metepisternos com pontos e pêlos iguais aos das laterais do metasterno. Élitros (Fig. 1) com pontuação forte e cerrada; epipleuras com pêlos curtos e esparsos na base; terço apical suavemente estreitado. Escultura do abdome formada por numerosos pequenos tubérculos (dos quais emerge um pêlo), seguidos de um sulco semicircular. Metade apical do último urosternito áspera e com pêlos mais longos e concentrados; ápice saliente e arredondado; borda externa com franja de pêlos. Coxas com pilosidade pouco conspícua. Fêmures com 

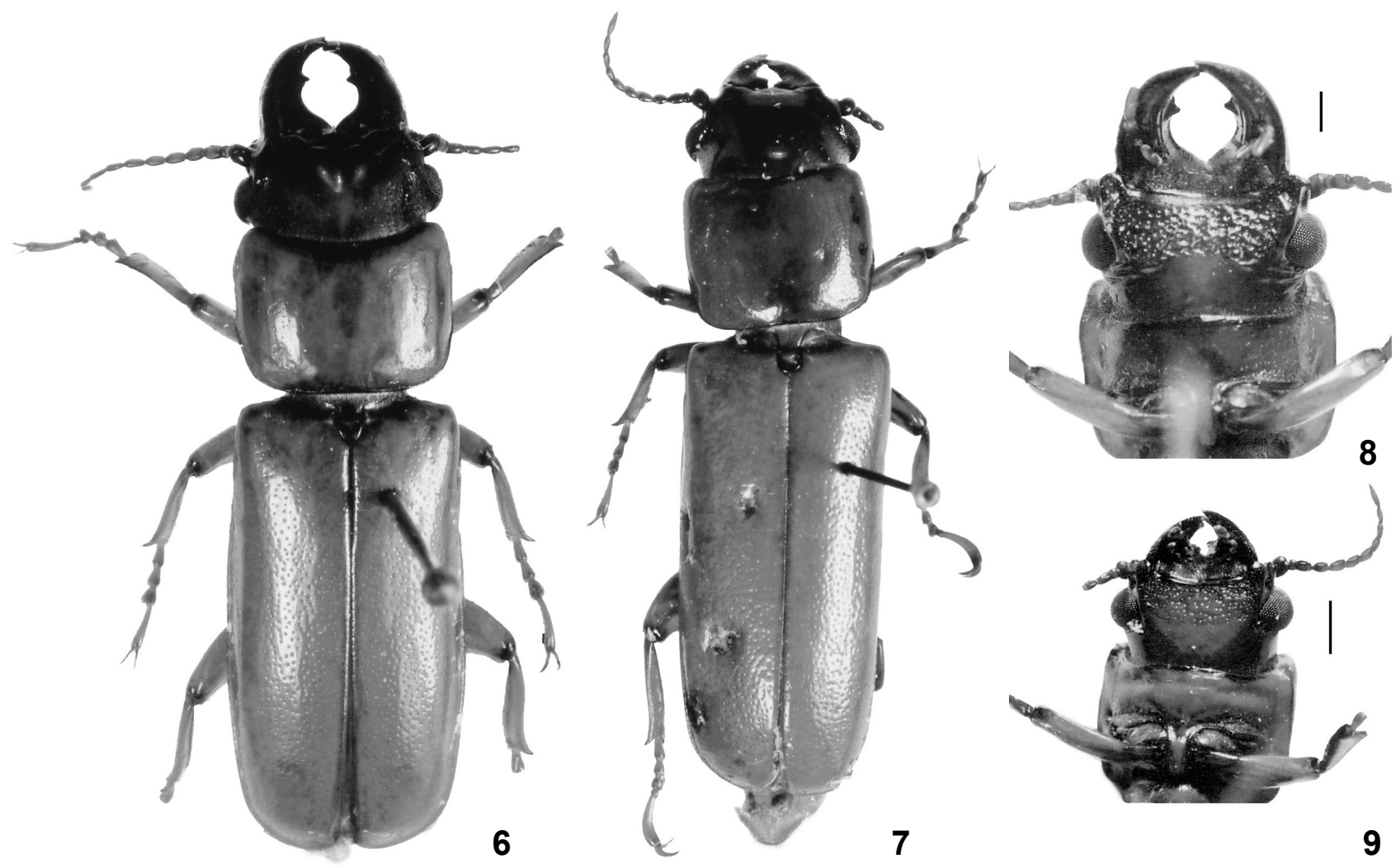

7

Figuras 6-9. Hesperandra scaritoides: (6) macho, vista dorsal, comprimento 25,0 mm; (7) fêmea, vista dorsal, comprimento 21,9 mm; (8-9) submento: (8) macho; (9) fêmea. Barra = $1 \mathrm{~mm}$.

pilosidade fina na face inferior. Tíbias (Fig. 19) pouco alargadas para o ápice, com pêlos maiores e mais concentrados no terço apical. Paroníquios com dois pares de setas.

Fêmea (Fig. 2). As principais diferenças em relação aos machos são: mandíbulas não-falciformes, margem interna com reentrância central forte; submento (Fig. 5) com a margem anterior elevada, mais estreita e com pontuação mais esparsa; pontuação da região posterior dos olhos mais fraca; protórax mais curto e menos estreitado em direção ao mesotórax.

Dimensões (macho/fêmea). Comprimento total, 16,126,7/26,8; comprimento do protórax no centro, 3,5-5,1/5,1; maior largura do protórax, 4,5-6,9/6,8; comprimento dos élitros, 10,1-14,7/15,8; largura umeral, 4,7-7,0/7,5.

Discussão. As localidades onde foram coletados os exemplares examinados, segundo a CARTA ECOLOGICA (1977), situamse em bosque muito úmido montano baixo (Arcabuco) e bosque seco montano baixo (Villa de Leyva e Paipa la Padrera). $H$. colombica apresenta pontuação elitral mais grossa e nítida do que em $H$. scaritoides e $H$. solangeae.

O holótipo, examinado através de diapositivo feito por J.S. Moure no British Museum, é um macho "minor".

Material examinado. Colômbia, Boyacá: Arcabuco (2600 m), fêmea, 11.V.1996, J.C. Mendoza leg. (UNCB); Villa de Leyva (atraído por luz, 2200 m), macho, 10.X.1996, F. Fernandez leg.
(IAHC); fêmea, XI.1996, C. Baena leg. (IAHC); (interior de casa, 2200 m), macho, 11.V.1997, M. Baena leg. (MZSP); (Corredor do Claustro San Augustin, 2200 m, noite, coleta manual), fêmea, 6.II.1998, C. Martínez leg. (MZSP); (Rua do Povoado, 2200 m, coleta manual), fêmea, 11.II.1999, C. Martínez leg. (IAHC); Paipa la Pradera (2650 m), fêmea, 2.XII.1978, Z. Arevolo G.S. leg. (UNCB).

\section{Hesperandra scaritoides (Thomson, 1861), sp. rev., comb. nov.}

Figs 6-11, 20

Parandra scaritoides Thomson, 1861: 82; 1867: 113; Lacordaire, 1869: 23 (nota); Bates 1872: 166 (distr.); Gemminger \& Harold, 1872: 2752 (cat.); Bates, 1879: 2; Lameere, 1902: 73 (syn.); 1913: 4 (cat., syn.); 1919: 15 (syn.); Blackwelder, 1946: 551 (cat., syn.); Arigony, 1978: 140 (syn.); Chemsak \& Linsley, 1982: 1 (cat., syn.); Chemsak et al., 1992: 13 (cat., syn.); Monné \& Giesbert, 1994: 1 (cat., syn.); Monné, 1994: 5 (cat., syn.); Maes et al., 1994: 3 (cat., syn.).

Parandra Scaritoïdes (sic); Thomson, 1878: 4 (tipo).

Redescrição. Macho (Fig. 6). Tegumento castanho. Cabeça e mandíbulas castanhas-escuras. Vértice convexo, com pontos 

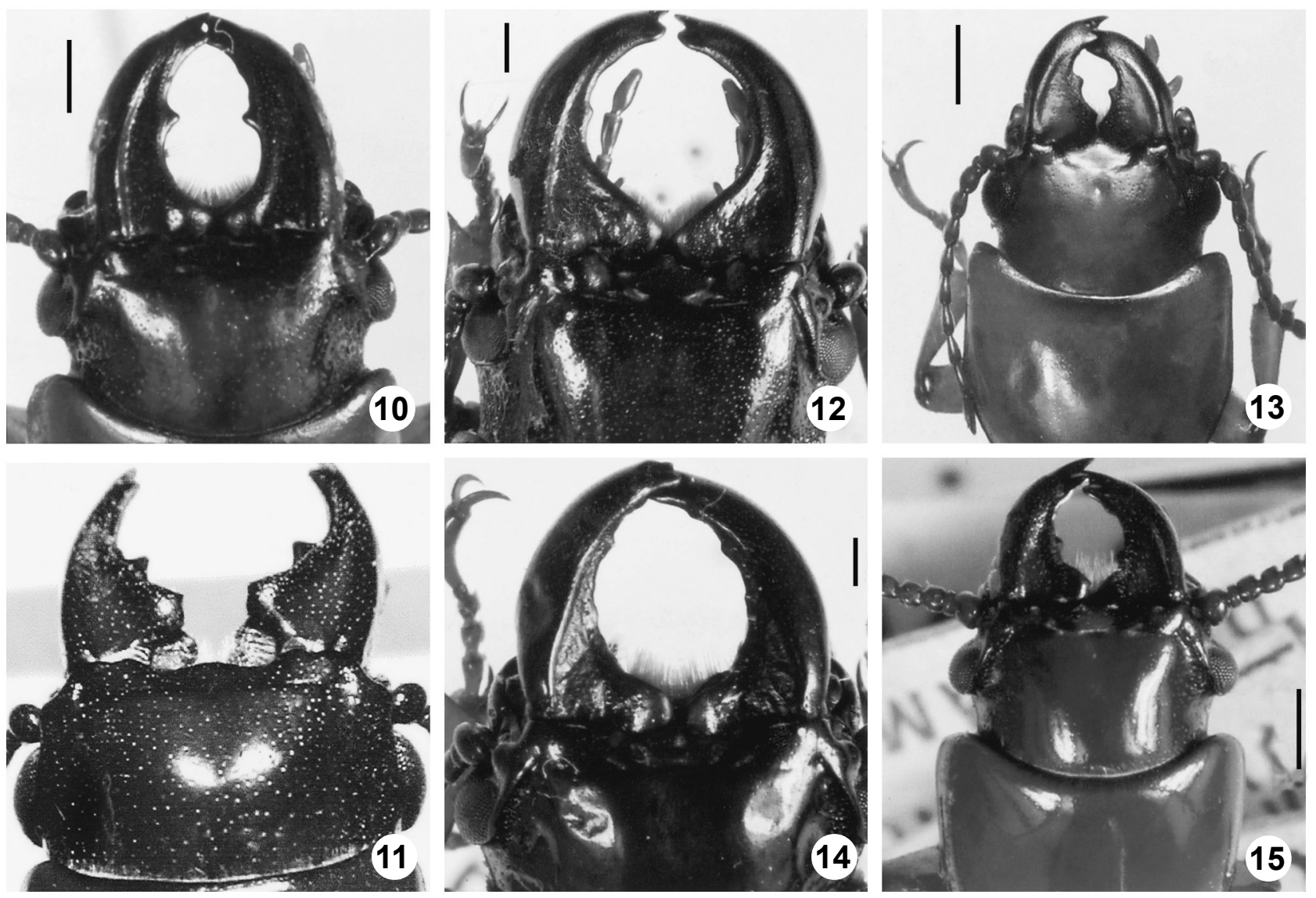

Figuras 10-15. Mandíbulas, vista dorsal. (10-11) Hesperandra scaritoides: (10) macho; (11) sintipo macho, foto G. L. Tavakilian. (12-13) Hesperandra glabra (De Geer, 1774): (12) macho major; (13) macho "minor". Hesperandra expectata (Lameere, 1902): (14) macho major; (15) macho "minor". Barra = $1 \mathrm{~mm}$.

pequenos e esparsos. Fronte com pontos menores do que os do vértice e igualmente esparsos. Região posterior dos olhos com pontos grossos e cerrados. Carena ocular pouco proeminente, sem sulco no lado interno, com pontos pequenos e esparsos. Suturas epistomal e clípeo-labral indicadas. Ápice do labro suavemente côncavo, aproximadamente no mesmo nível dos cantos anteriores da cabeça; borda anterior do labro com alguns pêlos microscópicos dirigidos horizontalmente para frente. Borda posterior dos olhos saliente. Face lateral das genas com pontos pequenos e esparsos, mais cerrados e abundantes junto à fóvea antenal; ápice genal pouco projetado e arredondado; em vista ventral, o ápice está em nível mais baixo do que a quilha genal e apresenta pontos pequenos e esparsos. Submento (Fig. 8) com a margem anterior lisa, glabra e plana, ou suavemente elevada e com pontos pequenos dispersos. Mandíbulas (Figs 10-11) falciformes, fortemente estreitadas para o ápice, pontuadas; carena dorsal forte na base, baixa em direção ao terço apical, onde desaparece; margem interna com um dente grande, aguçado, em proximidade do meio (nos exemplares estudados, a mandíbula direita apresenta ainda dois dentes indicados: um junto ao dente central e outro no terço apical); área dorso-interna, junto à margem, com pêlos muito curtos, principalmente na metade basal; ápice liso, com o dente apical externo fortemente agudo e o apical interno menor e em ângulo quase reto; região dorsal com depressão triangular longitudinal que se estende até o terço apical; base látero-externa com pêlos curtos. Carenas das áreas sensoriais dos antenômeros proeminentes; antenômeros II-XI com pêlos curtos nos ápices ventrais; $\mathrm{V}$-X com raros pêlos muito curtos no dorso; antenômero XI com pêlos esparsos no dorso e junto à carena da área sensorial; região dorsal do antenômero XI gradualmente curvada (sem ângulos).

Protórax transversal, marginação lateral enegrecida; ângulos anteriores arredondados; ângulos posteriores arredondados ou obtusos. Pronoto com pontos pequenos esparsos mais concentrados nas laterais, menores e mais dispersos no disco; borda anterior côncava e enegrecida. Prosterno com pêlos e pontos esparsos. Processo prosternal subplano, com ápice projetado. Mesosterno com pilosidade abundante. Mesepimeros e mesepisternos com pontos e pêlos esparsos. Metepisternos nitidamente pilosos. Metasterno com pontos e pêlos iguais aos dos metepisternos, com exceção da área central do disco, que é 


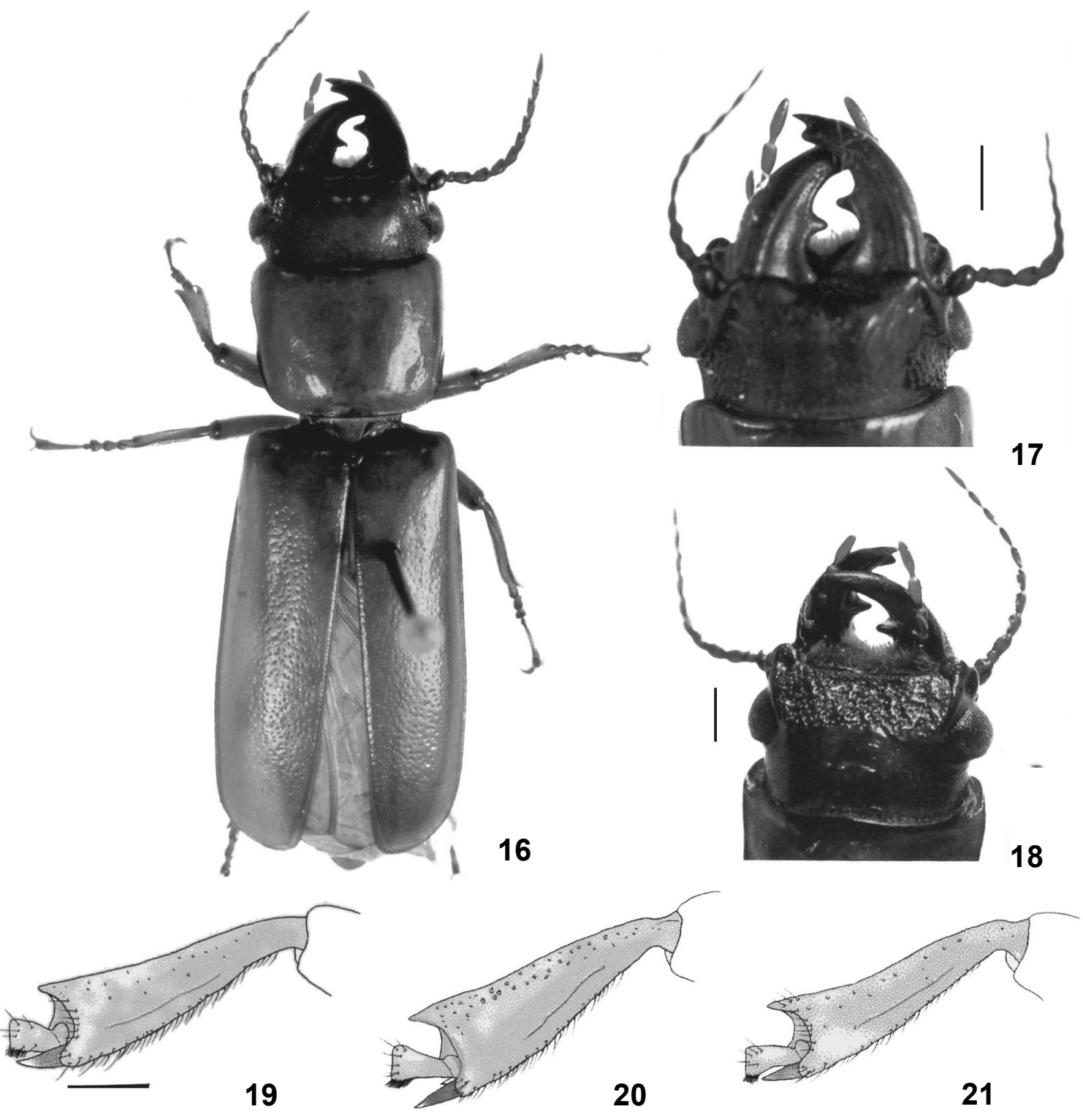

Figuras 16-21. (16-18) Hesperandra solangeae sp. nov., holótipo macho: (16) vista dorsal, comprimento 24,8 mm; (17) mandíbula, vista dorsal; (18) submento; (19-21) Protíbias, machos: (19) Hesperandra colombica; (20) Hesperandra scaritoides; (21) Hesperandra solangeae sp. nov. Barra $=1 \mathrm{~mm}$.

glabra. Élitros (Fig. 6) com pontos pequenos, bem visíveis e cerrados, principalmente na região central; epipleuras com pêlos esparsos na base; ápice arredondado. Urosternitos com tubérculos pequenos, dos quais emerge um pêlo, seguidos de um sulco semi-circular; metade apical do último urosternito com tubérculos mais salientes. Coxas com pêlos esparsos. Fêmures com pilosidade bem visível na borda inferior. Tíbias (Fig. 20) muito alargadas para o ápice, com pêlos maiores e mais concentrados também em direção ao ápice. Paroníquios com dois pares de setas.
Fêmea (Fig. 7). Ápice do clípeo-labro mais projetado; mandíbulas não-falciformes, com forte reentrância na margem interna; submento (Fig. 9) com pontos mais esparsos e menores; protórax menos transversal.

Variabilidade. No sintipo macho (Fig. 11) as mandíbulas são mais curtas e alargadas na base; o dente da margem interna localiza-se um pouco antes do meio e a mandíbula esquerda apresenta um dente menor junto ao outro dente. Esse tipo de variação na forma das mandíbulas é freqüente em Parandrinae (Figs 12-15), principalmente em machos "minor". 
Dimensões (macho/fêmea). Comprimento total, 25,026,3/21,2-21,9; comprimento do protórax no centro, 4,6-4,8/ 4,2-4,4; maior largura do protórax, 6,8-7,1/5,5-5,6; comprimento dos élitros, 13,5-14,5/12,9-13,0; largura umeral, 6,8-7,2/ 6,0-6,1.

Discussão. As localidades onde foram coletados os exemplares estudados, segundo a CarTa Ecologica (1977), situam-se em bosque muito úmido pré-montano (Pajarito), bosque úmido montano baixo (Chiquinquirá), zona de transição entre bosque seco pré-montano e bosque seco montano baixo (Guacamayas).

Lameere (1902) colocou Parandra scaritoides na sinonímia de $P$. colombica, sem ver os sintipos, que se encontram depositados no MNHN, baseando-se unicamente na descrição apresentada por THомson (1861). H. scaritoides difere de H. colombica pelo protórax mais transversal, pontuação elitral mais fraca e pelas mandíbulas mais longas.

A redescrição foi baseada nos espécimes listados abaixo, no exame de diapositivo de dois sintipos (no qual só é possível ver os élitros), feito por J.S. Moure e fotos do sintipo macho, enviadas por G. Tavakilian. Тномsоn (1861) apresentou as medidas de um só exemplar: "Long. 21 mill.; lat. 6 mill."; na descrição, comentou: "Mandíbulae \% capitis longitudine, arcuatae, supra a base usque just medium subtriangulariter excavatae, intus pluridentatae, apice bifidae, sat valde et confertim punctatae, apud \& minores", e ainda, nas observações: "Ces caractères sont plus que suffisants pour distinguer la P. cylindrica de l'espèce actuelle, dont je ne possède qu'un seul individu". Essa última afirmativa concorda com a única medida apresentada, mas é conflitante com o trecho da descrição apresentado acima; vale ressaltar, que na descrição de Parandra cylindrica (THOMson 1861), foram apresentadas mais de uma medida, indicando que mais de um exemplar foi examinado. Segundo Tavakilian (comunicação pessoal) apenas um tipo macho foi localizado na coleção MNHN.

Material examinado. ColômBIA, Boyacá: Chiquinquirá, fêmea, 13.II.1969, J. Abrato leg. (MZSP); Guacamayas (em tronco de salgueiro), macho, XII.1980, G. Mendonza leg. (GMIC); Pajarito $\left(5^{\circ} 25^{\prime} \mathrm{N}, 72^{\circ} 40^{\prime} \mathrm{W}\right)$, macho, 10.XI.1977, CO-2334, E. Linz leg..(MUJB). Província ?: Laguna Seca (?), fêmea, 10.I.1965, Sergio Restuspo leg. (MZSP).

\section{Hesperandra solangeae sp. nov. Figs 16-18, 21} (DZUP).

Etimologia. Homenagem à Dra. Dilma Solange Napp

Macho (Fig. 16). Tegumento castanho. Cabeça e mandíbulas castanhas-escuras. Vértice subplano, com pontos pequenos e esparsos. Pontuação da fronte microscópica. Região posterior dos olhos com pontuação forte e cerrada (os pontos diminuem de tamanho e concentração em direção à gula). Carena ocular fraca e com sulco marginal largo e raso. Borda posterior dos olhos saliente. Região lateral das genas com pontuação evidente; ápice pouco projetado, arredondado e com pontos dispersos no lado ventral; carena genal baixa, de forma que o submento é visível em vista lateral. Submento (Fig. 18) com pontuação grossa e anastomosada; pilosidade abundante, mais concentrada em direção às genas; borda anterior suavemente elevada. Mandíbulas (Fig. 17) falciformes, pontuadas, não-fortemente estreitadas no ápice; carena dorsal forte na base, baixa em direção ao ápice; margem interna com um dente grande no meio, aguçado, e outro apenas indicado no terço basal; pilosidade da margem interna constituída por franja de diminutos pêlos; região látero-externa com pêlos curtos e esparsos na base. Antenômeros III-X com pêlos curtos no terço dorso-apical; antenômero XI com pêlos junto à carena da área sensorial e face dorsal; carena da área sensorial dos antenômeros III-XI pouco visível em vista lateral.

Protórax transversal, estreitado para a base; ângulos anteriores e posteriores arredondados; sinuosidade da borda lateral fraca. Pronoto com pontos finos e rasos, mais agrupados nas laterais. Prosterno com pontos e pêlos pouco concentrados (ligeiramente mais cerrados próximo às coxas). Mesosterno com pêlos e pontos abundantes. Mesepisternos e mesepimeros com pontos e pêlos menos conspícuos do que no mesosterno, porém bem visíveis. Metepisternos com pontuação e pilosidade fortes. Metasterno com pilosidade e pontuação iguais às dos metepisternos (a concentração e o tamanho diminuem em direção ao centro do disco). Pontuação elitral bem visível, mais concentrada na metade apical. Epipleuras com pêlos diminutos na base. Urosternitos com tubérculos pequenos e esparsos, dos quais emerge um pêlo, seguidos de um sulco semicircular; metade apical do último urosternito com tubérculos mais salientes. Tíbias (Fig. 21) pouco alargadas para o ápice, com pêlos maiores e mais concentrados no terço apical.

Fêmea desconhecida.

Dimensões, macho. Comprimento total, 24,8; comprimento do protórax no centro, 4,8; maior largura do protórax, 6,3; comprimento dos élitros, 13,4; largura umeral, 6,5.

Discussão. Esta espécie difere de $H$. scaritoides pela forma do protórax e das tíbias e de $H$. colombica pela forma das mandíbulas e pontuação elitral.

Material-tipo. Venezuela, Mérida: La Mucuy $(10 \mathrm{~km} \mathrm{E}$ Tabay; 200 m; atraído por luz), holótipo macho, 27.IV.1981, L. Masner leg. (MZSP).

\section{AGRADECIMENTOS}

À Claudia Martinez (IAHC), pelo empréstimo de material do GMIC, IAHC e MUJB; ao Dr. Gerard L. Tavakilian (MNHN), pelo exame e envio de fotos de um dos síntipos de Parandra scaritoides; ao Dr. Ubirajara R. Martins (MZSP), pelo constante apoio e incentivo.

\section{REFERÊNCIAS BIBLIOGRÁFICAS}

Arigony, T.H.A. 1978. Revisão do gênero Parandra (Coleoptera, Cerambycidae). 1. O Subgênero Hesperandra Arigony, 1977. Revista Brasileira de Entomologia, São Paulo, 22 (3/4): 119-159.

Bates, H.W. 1872. On the longicorn Coleoptera of Chontales, Nicaragua. The Transactions of the Entomological Society of London, London, 1872: 163-238.

1879. In: F.D.C. Goldman \& O. Salvin (Eds). Biologia Centrali-Americana, Insecta, Coleoptera. London, British Museum (Natural History), vol. 5, p. 1-16.

Blackwelder, R.E. 1946. Checklist of the Coleopterous Insects of Mexico, Central America, the West Indies and South America, Part 4. Bulletin of the United States National Museum, Washington, D.C., 185: 551-763.

Carta Ecologica, 1977. Carta ecológica. Bogotá, Ministerio de Hacienda Y Credito Publico, Instituto Geografico "Augustin

Revista Brasileira de Zoologia 20 (3): 389-395, setembro 2003 
Codazzi", Subdireccion Agrologica, 21 mapas.

ChemsaK, J.A. \& E.G. LINSLey. 1982. Checklist of Cerambycidae. The Longhorned beetles. Checklist of the Cerambycidae and Disteniidae of North America, Central America, and the West Indies (Coleoptera). Medford, Plexus, 138p.

Chemsak, J.A.; E.G. Linsley \& F.A. Noguera. 1992. Listados Faunisticos de Mexico II. Los Cerambycidae y Disteniidae de Norteamerica, Centroamerica y las Indias Occidentales (Coleoptera). México, Universidad Nacional Autónoma de Mexico, Instituto de Biologia, 204p.

Gemminger, M. \& E. Harold. 1872. Catalogus Coleopterorum hucusque descriptorum synonymicus et systematicus, Monachii, 9: 2669-2988.

KIRSCH, T.F. 1889. Coleopteren gesammelt in den Jahren 18681877 auf einer Reise durch Süd Amerika von Alphons Stübel. Abhandlungen und Berichte des königlichen Zoologischen und Anthropologisch-Ethnographischen Museums, Dresden, 4: 1-58.

LACORDAIRE, J.T. 1869. Histoire Naturelle des Insectes. Genera des Coléoptères. Paris, Librairie Encyclopedique de Roret, 8: $1-552$.

LAMEere. A. 1902. Révision des prionides (Premier mémoire Parandrines). Annales de la Société Entomologique de Belgique, Bruxelles, 46: 59-111.

. 1913. Coleopterorum Catalogus, pars 52, Cerambycidae: Prioninae. Berlin, W. Junk, 180 p.

- 1919. Genera Insectorum, Coleoptera, Fam. Cerambycidae, Subfam. Prioninae. Bruxelles, P. Wytsman, v. $172,189 \mathrm{p}$.

Maes, J.M.; A. Allen; M.A. Monné \& F.T. Hovore. 1994. Catálogo de Los Cerambycidae (Coleoptera) de Nicaragua. Revista Nicaraguense de Entomologia, León, 27: 1-58.

Martínez, C. 2000. Escarabajos Longicornios (Coleoptera:
Cerambycidae) de Colombia. Biota Colombiana, Santafé de Bogotá, 1 (1): 76-105.

Monné, M.A. 1994. Catalogue of the Cerambycidae (Coleoptera) of the Western Hemisphere. Part XII. São Paulo, Sociedade Brasileira de Entomologia, 56p.

Monné, M.A. \& E.F. Giesbert. 1994. Checklist of the Cerambycidae and Disteniidae (Coleoptera) of the Western Hemisphere. Burbank, Wolfsgarden Books, 410p.

Prudhomme. 1906. Catalogue des Coléoptères de la Guyane Française recueillis par M. Prudhomme de 1870 à 1906. Cayenne, Imprimerie du Gouvernement, 46p.

RoJAs, M.A. 1866. Catalogue des longicornes de la province de Caracas, République de Venezuela avec quelques observations sur leurs habitudes. Annales de la Société Entomologique de France, Paris, (4) 6: 236-248.

Rosales, C.J. 1966. Contribucion al conocimiento de los Prioninae (Coleóptera: Cerambycidae) de Venezuela. Revista de la Faucultad de Agronomia de la Universidad Central de Venezuela, Maracay, 11: 1-237.

SANTOS-SILVA, A. 2003. Notas, descrições, sinonímias e revalidação em Hesperandra Arigony, 1977 (Coleoptera, Cerambycidae, Parandrinae). Revista Brasileira de Entomologia, Curitiba, 47 (1): 119-131.

Thomson, J. 1861. Monographie de la famille des parandrines. Museé Scientifique, Paris, 2: 73-87.

. 1867. Révision des Parandrides (Insectes Coléoptères). Physis Recueil d'Histoire Naturelle, Paris, 1 (2): 106118.

. 1878. Typi cerambycidarum Musei Thomsoniani. Paris, E. Deyrolle, 21p.

White, A. 1853. Catalogue of the coleopterous insects in the collection of the British Museum, Longicornia 1. London, vol. 7, 174p.

Recebido em 09.I.2003; aceito em 02.VI.2003. 